\title{
BMJ Open Socioeconomic differences in mortality among 27 million economically active Germans: a cross-sectional analysis of the German Pension Fund data
}

To cite: Grigoriev P, Scholz R, Shkolnikov VM. Socioeconomic differences in mortality among 27 million economically active Germans: a cross-sectional analysis of the German Pension Fund data. BMJ Open 2019;9:e028001. doi:10.1136/ bmjopen-2018-028001

- Prepublication history and additional material for this paper are available online. To view these files, please visit the journal online (http://dx.doi org/10.1136/bmjopen-2018028001).

Received 22 November 2018 Revised 20 June 2019 Accepted 16 August 2019

\section{Check for updates}

(c) Author(s) (or their employer(s)) 2019. Re-use permitted under CC BY-NC. No commercial re-use. See rights and permissions. Published by BMJ.

${ }^{1}$ Max Planck Institute for Demographic Research, Rostock, Germany

${ }^{2}$ National Research University Higher School of Economics, Moscow, Russian Federation

Correspondence to

Dr Pavel Grigoriev;

grigoriev@demogr.mpg.de

\section{ABSTRACT}

Objectives To assess disparities in mortality by socioeconomic status in Germany.

Design and participants We analyse a large administrative dataset of the German Pension Fund (DRV), including 27 million person-years of exposure and 42000 deaths in 2013. The data cover the economically active population, stratified by sex and by East and West. Outcome measures Age-standardised mortality rates and Poisson regression mortality rate ratios (MRRs). Results The risk of dying increases with decreasing income: the MRRs of the lowest to the highest income quintile are $4.66(95 \% \mathrm{Cl} 4.48$ to 4.85$)$ among men and 3.06 (95\% Cl 2.90 to 3.23$)$ among women. The impact of income attenuates after controlling for education and other explanatory variables, especially for females. In the fully controlled model for females, individual income is a weaker predictor of mortality, but there is a clear educational mortality gradient. In the fully controlled model, the MRRs of the unemployed to the employed are 2.09 (95\% Cl 2.03 to 2.15$)$ among men and 2.01 (95\% Cl 1.92 to 2.10 ) among women. The risk of dying is around half as high among foreigners as among German citizens. The socioeconomic disparities are greater among East than West German men.

Conclusions Low socioeconomic status is a major determinant of excess adult mortality in Germany. The persisting East-West differences in male adult mortality can be explained by the higher socioeconomic status of men living in the West, rather than by contextual differences between East and West. These differences can be further monitored using DRV data.

\section{INTRODUCTION}

The reduction of mortality disparities across socioeconomic groups is an important public health priority. ${ }^{1}$ A large body of literature shows that disparities between socioeconomic groups persist or even increase with time. ${ }^{2-5}$ In several high-income countries, data on deaths have been linked to census or register information on socioeconomic status (SES), and mortality by SES group has been computed. Such analyses are not possible in Germany because of the country's data
Strengths and limitations of this study

- Using a large administrative dataset of the German Pension Fund (DRV), this study provides the first population-level estimates on socioeconomic mortality differentials across the economically active population of Germany.

- Mortality disparities are assessed using a broad range of socioeconomic and demographic characteristics, including individual income, education, employment status, citizenship and region.

- The DRV data, particularly on individual income, are highly reliable because the information reported by employers serves as the basis for pension entitlements in the future.

- There is a relatively large share of missing values for the education variable, primarily because people who were unemployed or out of the labour market for other reasons had no employer to report the information on education.

- Our analyses do not cover individuals of working ages who are receiving pensions due to disability.

protection rules. Thus, despite being the EU country with the largest population and the greatest economic power, Germany is missing in many international comparisons of health disparities. $^{6-9}$

Because of the unavailability of population-level statistics, most of the existing evidence about mortality variation by SES in Germany is based on survey estimates. ${ }^{10-16}$ Unfortunately, surveys like the German Socio-Economic Panel (SOEP) are not designed for the assessment of mortality by SES. First, the statistical power of such data is often insufficient for estimating mortality by SES due to the small numbers of death events. Second, it is often not possible to check the vital status of individuals due to a lack of informants. Third, the surveys seldom cover individuals who live on the margins and have particularly high mortality risks. Because the existing survey-based studies 
differ with respect to their data and methods, definitions and analysed subpopulations, it is difficult to generalise and compare their results. In their survey-based study of differential mortality in West Germany, Luy et $a l^{12}$ provided a thorough overview of the state of the art in Germany, and concluded that '... reliable estimates with regard to the extent of the differentials that can be assessed in an international context, and that consider different SEP dimensions, are missing for the German population'. In an attempt to address this knowledge gap, the authors (on the basis of certain assumptions) estimated life expectancy by education, household income, work status and vocational group for German citizens living in West Germany. This work relied on survey data from the early 1990s, and employed indirect methods of mortality estimation. The study found striking differences in life expectancy at age 40 across the analysed SES dimensions, particularly for men: life expectancy at age 40 among men varied by more than $>5$ years between the lowest and the highest household income categories, by more than $>6$ years between individuals with low and high levels of education, by around 10 years across the employment status categories and by almost 15 years across the vocational classes. ${ }^{12}$

Recently, Germany has implemented policies that provide researchers with access to administrative microdata. von Gaudecker and Scholz, ${ }^{17}$ Shkolnikov et al, ${ }^{18}$ Kibele $e t a l^{19}$ and Wenau $e t a l^{20}$ took advantage of data from the German Pension Insurance Union (Deutsche Rentenversicherung Bund; hereafter DRV) to analyse mortality differentials among Germans aged 65+. While we also use DRV data, unlike previous studies we examine mortality disparities in Germany's working-age population; and we assess these mortality differentials using a broader range of SES characteristics, including income, education and employment status. Although the association of these characteristics with mortality is well-documented, ${ }^{1-7}$ it has been shown that different SES indicators are not fully interchangeable, as each has its own specific effect on mortality. ${ }^{21}{ }^{22}$ We also carry out a comparative analysis of differences between East and West Germany in mortality by SES, and of the role of SES in the persisting East-West gap in midlife male mortality. ${ }^{23}$

\section{METHODS \\ DRV data}

The legal issues, principles and concepts related to the administration and maintenance of the DRV databases have been described in detail elsewhere. ${ }^{24-26}$ Here, we distinguish between two DRV datasets. The first dataset consists of records on all pensions paid by the DRV. The pension recipients are former employees who left work due to disability (Erwerbsminderungsrenten; hereafter EMR). The second database contains records on contributions paid by the economically active insured population (Aktiv Versicherte; hereafter AKV). Participation in the statutory pension insurance scheme is mandatory in
Germany for all working individuals except the self-employed and civil servants. Both the EMR and AKV datasets provide information on the demographic and socioeconomic characteristics of the population, as well as on the number of death events. However, because the characteristics covered in the two data sets are not comparable, a detailed analysis of the combined (AKV+EMR) dataset is not possible. Notably, the inactive population covered by the EMR dataset cannot be properly classified by education and employment status. Moreover, the income variable in the EMR dataset is not comparable to that in the AKV dataset. The former is based on the pension points accumulated over a lifetime, while the latter refers to current income.

Consequently, our main analyses are based on the AKV data for the year 2013, which we obtained through the FDZ-DRV (Forschungsdatenzentrum-DRV Research Data Centre) in Berlin. ${ }^{26}$ The centre was created in 2006 to facilitate scientific data use. ${ }^{2728}$

The DRV data collection system functions as a population register that (unlike the Nordic population registers) focuses exclusively on people's employment and educational careers, and on other factors that influence people's rights to retire and collect a pension. DRV follows up everyone who contributes to the German economy. This study looks at the reporting year from 31 December 2012 to 31 December 2013. To estimate mortality in 2013, we relied on three datasets: 1) individual records on living individuals at the end of 2012,2) similar records at the end of 2013 and 3) records on deaths that occurred during 2013. We linked records on living individuals with corresponding death records and assigned to each individual his/her exposure time and vital (alive/deceased) status at the end of 2013. On completing our work at the FDZ, we received the data in the form of a frequency table in which the deaths and the corresponding exposures were classified according to all possible combinations of the sociodemographic variables.

Our analysis includes the population aged $30-59$ years. The lower age limit was chosen based on the assumption that educational status changes little after age 30 . Although the AKV data include information up to age 65, people aged 60-64 years were excluded from the analysis, as many would have left the AKV to retire early (possible after age 63) or collect a disability pension. As the early retirement is correlated with poor health, the remaining AKV population aged 60-64 years is substantially smaller, more selective and experiences implausibly low death rates compared with the population aged 55-59 years.

The final AKV dataset used in the analysis contains data on 42200 deaths and 27.1 million person-years of observation; or $50 \%$ of all deaths that occurred in 2013 and $80 \%$ of the total German population for those aged 30-59 years. ${ }^{29}$ The EMR dataset for the same ages includes 25500 deaths and 1.2 million person-years $(30 \%$ and $3.5 \%$, respectively). Figure 1 indicates that mortality is 9 times higher among men and is 14 times higher among women in the EMR than in the AKV population. 

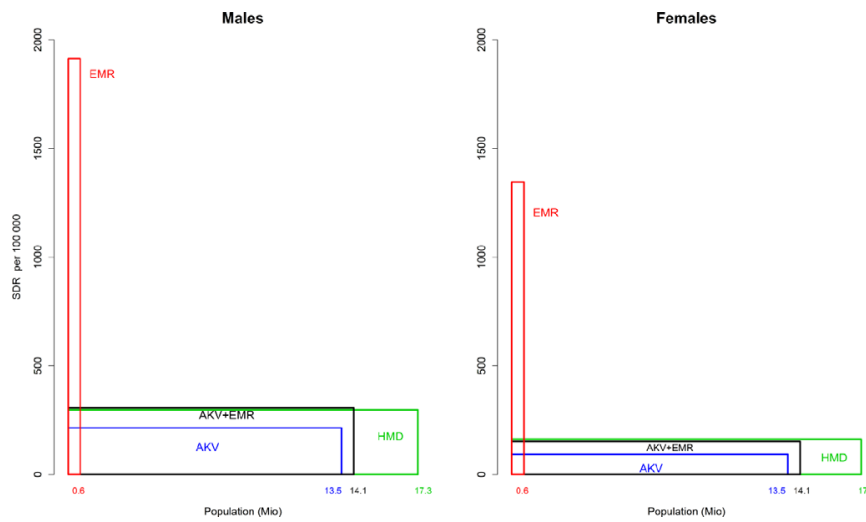

Figure 1 Standardised mortality rate (SDR) (per 100 000) and corresponding population size (million) by data source, ages 30-59 years, 2013. EMR (Erwerbsminderungsrenten)population receiving disability pensions $(\operatorname{SDR}(\mathrm{m})=1912$, $\operatorname{SDR}(\mathrm{f})=1345$, population $(\mathrm{m})=0.603$, population $(\mathrm{f})=0598)$; AKV (Aktiv Versicherte)-economically active insured population $(\operatorname{SDR}(m)=215$, SDR $(f)=93$, population $(m)=13543$, population $(\mathrm{f})=13513) ; \mathrm{AKV}+\mathrm{EMR}-\mathrm{combined} \mathrm{AKV}$ and ERM population $(\operatorname{SDR}(\mathrm{m})=306$, SDR $(\mathrm{f})=151$, population $(m)=14146$, population $(f)=14111)$; HMD - Human Mortality Database $(\operatorname{SDR}(\mathrm{m})=297, \operatorname{SDR}(\mathrm{f})=161$, population $(\mathrm{m})=17317$, population $(f)=17107)$.

Therefore, the exclusion of the EMR population from the analysis explains why the AKV-based mortality rates are lower than the mortality rates for the total national population presented in the Human Mortality Database (HMD). ${ }^{29}$ The age-standardised mortality rates (SDRs) calculated from the combined (AKV+EMR) data are nearly identical to the respective rates for the entire German population (HMD). This suggests that the German pension data are highly reliable.

The following characteristics are considered in the analysis: age, sex, region (East, West), citizenship (foreign, German), employment (employed, unemployed), income (quintile of the current pension income) and education.

In DRV data, foreigners are individuals who have current citizenship of other countries (holders of foreign passports). Individuals who were unemployed and were searching for job for at least 1 day in the year of reporting or the previous year are defined by the DRV data as unemployed. The information on education was extracted from the nine-digit occupation key (Tätigkeitsschlüssel) based on the German Classification of Professions (KldB 2010). We use four educational categories: i) lower, which includes no diploma (ohne Schulabschluss) and lower secondary education (Haupt/Volkschulabschluss); ii) secondary (Mittlere Reife oder gleichwertiger Abschluss); iii) higher, which includes tertiary education (Abitur/Fachabitur) and iv) unknown (fehlender Wert, Abschluss unbekannt). ${ }^{30}$ Unfortunately, around $40 \%$ of the education variable values turned out to be unknown, primarily because people who were unemployed or out of the labour market for other reasons had no employer to report the educational information. Additional tabulation (not shown here) indicates that roughly $60 \%$ of the males with unknown education were either unemployed or belonged to the lowest income quintile. This observation is consistent with the literature suggesting that individuals with unknown education tend to be the least educated. ${ }^{31}{ }^{32}$ We, therefore, decided to treat the unknown category separately, rather than to redistribute it proportionally among the other educational categories.

\section{Statistical analyses}

To evaluate mortality differentials, we used both empirical and model-based mortality measures. For each socioeconomic category, we computed age-specific mortality rates and SDRs using the European population standard. ${ }^{33}$ The model-based mortality rate ratios (MRRs) resulted from the Poisson model, with a log link and a logarithm of person-years being used as an offset (function $\mathrm{glm}$ in $\mathrm{R})$.

We assessed mortality disparities using the measure of combined relative mortality risk (combined MRR). Here, we used the mutually adjusted MRRs for all combinations of the values of two SES variables: education and income. These two-dimensional risk estimates were based on the assumption that the explanatory variables with no interaction presented additive risks. An example of the calculation of a combined MRR is given in the 'Results' section.

In our sensitivity analysis we used the Multivariate Imputation by Chained Equations (MICE) algorithm implemented in $\mathrm{R}$ package mice. ${ }^{34}$ The method assumes the imputation of unknown values for the variable of interest on the basis of relationships between known education values and other variables (predictors).

\section{Patient and public involvement}

Patients or public were not involved.

\section{RESULTS}

Mortality differentials by socioeconomic characteristics

The results of the analysis on the AKV data are summarised in table 1 . Because of the large sample sizes, we do not report (very narrow) confidence limits for the SDRs. Along with the SDRs, we show the two types of modelbased MRRs: i) age-adjusted with the variable of interest and age included (model 1) and ii) fully adjusted MRRs with age and all explanatory variables included simultaneously (model 2).

Of the variables used in the analysis, the differentials are particularly large for employment, income and education. The SDR values show how the absolute level of mortality varies across sociodemographic groups. This variation is greater among males than among females.

The outcomes of the mutually adjusted model 2 differ considerably from those of model 1 . In particular, the advantage of West German males relative to their East German counterparts found in model 1 disappears after controlling for other variables. The effects of male 
Table 1 Standardised death rate (SDR) and model-based mortality rate ratio (MRR) by sociodemographic categories (2013, ages $30-59$ years)

\begin{tabular}{|c|c|c|c|c|c|}
\hline \multirow[b]{2}{*}{ Males } & \multirow{2}{*}{$\begin{array}{l}\text { Person-years of } \\
\text { exposure }\end{array}$} & \multirow[b]{2}{*}{ Deaths } & \multirow{2}{*}{$\begin{array}{l}\text { SDR, per } \\
100000\end{array}$} & \multicolumn{2}{|l|}{ Model-based MRR } \\
\hline & & & & Model 1 & Model 2 \\
\hline \multicolumn{6}{|l|}{ Region } \\
\hline Eastern Germany & 2402169 & 6447 & 251.5 & 1.00 (ref) & 1.00 (ref) \\
\hline Western Germany & 11019226 & 22349 & 200.4 & $0.79^{* * *}(0.77-0.82)$ & $1.04^{* * *}(1.01-1.07)$ \\
\hline Unknown & 121583 & 556 & 455.4 & $1.82^{\star \star \star}(1.67-1.98)$ & $2.56^{\star \star \star}(2.34-2.79)$ \\
\hline \multicolumn{6}{|l|}{ Nationality } \\
\hline Foreign & 1598249 & 2123 & 154.8 & 1.00 (ref) & 1.00 (ref) \\
\hline Germany & 11944729 & 27229 & 217.8 & $1.41^{\star \star *}(1.35-1.47)$ & $2.03^{\star * *}(1.94-2.12)$ \\
\hline \multicolumn{6}{|l|}{ Employment } \\
\hline Employed & 10850485 & 16735 & 149.2 & 1.00 (ref) & 1.00 (ref) \\
\hline Unemployed & 2692493 & 12617 & 478.1 & $3.22^{\star \star \star}(3.15-3.30)$ & $2.09^{\star \star \star}(2.03-2.15)$ \\
\hline \multicolumn{6}{|l|}{ Education } \\
\hline Higher & 2616949 & 2665 & 113.8 & 1.00 (ref) & 1.00 (ref) \\
\hline Secondary & 2832094 & 4299 & 152.9 & $1.36^{* * *}(1.30-1.43)$ & $1.12^{\star \star \star}(1.07-1.18)$ \\
\hline Lower & 3232296 & 6465 & 187.8 & $1.67^{\star \star \star}(1.60-1.75)$ & $1.29^{\star \star \star}(1.23-1.35)$ \\
\hline Unknown & 4861639 & 15923 & 305.4 & $2.72^{\star * *}(2.61-2.84)$ & $1.57^{\star \star \star}(1.50-1.64)$ \\
\hline Test for linear trend & & & & $P=0.046$ & $P=0.018$ \\
\hline \multicolumn{6}{|l|}{ Income quintile } \\
\hline 1 & 2329163 & 11243 & 469.4 & $4.66^{\star \star \star}(4.48-4.85)$ & $2.49^{\star \star \star}(2.37-2.61)$ \\
\hline 2 & 2736943 & 6062 & 233.5 & $2.33^{\star * \star}(2.24-2.43)$ & $1.66^{* * *}(1.59-1.75)$ \\
\hline 3 & 2817235 & 4823 & 171.3 & $1.71^{\star \star \star}(1.63-1.79)$ & $1.46^{\star \star \star}(1.39-1.53)$ \\
\hline 4 & 2826523 & 4107 & 139.5 & $1.39^{* * *}(1.33-1.46)$ & $1.28^{\star \star \star}(1.22-1.34)$ \\
\hline 5 & 2833114 & 3117 & 100.4 & 1.00 (ref) & 1.00 (ref) \\
\hline \multicolumn{3}{|l|}{ Test for linear trend } & & $P=0.037$ & $P=0.017$ \\
\hline \multirow[b]{2}{*}{ Females } & \multirow{2}{*}{$\begin{array}{l}\text { Person-years of } \\
\text { exposure }\end{array}$} & \multirow[b]{2}{*}{ Deaths } & \multirow{2}{*}{$\begin{array}{l}\text { SDR, per } \\
100000\end{array}$} & \multicolumn{2}{|l|}{ Model-based MRR } \\
\hline & & & & Model 1 & Model 2 \\
\hline \multicolumn{6}{|l|}{ Region } \\
\hline Eastern Germany & 2402613 & 2176 & 83.8 & 1.00 (ref) & 1.00 (ref) \\
\hline Western Germany & 11030615 & 10373 & 92.8 & $1.12^{\star \star *}(1.07-1.17)$ & $1.25^{\star \star \star}(1.19-1.31)$ \\
\hline Unknown & 79682 & 270 & 343.8 & $4.12^{\star \star \star}(3.63-4.68)$ & $4.80^{\star \star}(4.22-5.46)$ \\
\hline \multicolumn{6}{|l|}{ Nationality } \\
\hline Foreign & 1417246 & 867 & 72.7 & 1.00 (ref) & 1.00 (ref) \\
\hline Germany & 12095664 & 11952 & 94.2 & $1.29^{\star \star \star}(1.21-1.39)$ & $1.96^{\star \star *}(1.83-2.11)$ \\
\hline \multicolumn{6}{|l|}{ Employment } \\
\hline Employed & 11007692 & 8332 & 72.4 & 1.00 (ref) & 1.00 (ref) \\
\hline Unemployed & 2505218 & 4487 & 188.9 & $2.62^{\star \star \star}(2.52-2.71)$ & $2.01^{\star \star \star}(1.92-2.10)$ \\
\hline \multicolumn{6}{|l|}{ Education } \\
\hline Higher & 2367803 & 1221 & 59.2 & 1.00 (ref) & 1.00 (ref) \\
\hline Secondary & 3780230 & 2528 & 65.1 & $1.09^{\star \star}(1.02-1.17)$ & $1.08^{* *}(1.01-1.16)$ \\
\hline Lower & 2211302 & 2181 & 85.4 & $1.45^{\star \star \star}(1.35-1.55)$ & $1.30^{\star \star \star}(1.21-1.40)$ \\
\hline Unknown & 5153574 & 6889 & 127.9 & $2.15^{\star \star \star}(2.02-2.29)$ & $1.60^{\star * *}(1.50-1.71)$ \\
\hline Test for linear trend & & & & $P=0.059$ & $P=0.029$ \\
\hline \multicolumn{6}{|l|}{ Income quintile } \\
\hline 1 & 2328066 & 4029 & 202.3 & $3.06^{\star \star \star}(2.90-3.23)$ & $1.75^{\star \star \star}(1.64-1.86)$ \\
\hline
\end{tabular}


Table 1 Continued

\begin{tabular}{|c|c|c|c|c|c|}
\hline \multirow[b]{2}{*}{ Females } & \multirow{2}{*}{$\begin{array}{l}\text { Person-years of } \\
\text { exposure }\end{array}$} & \multirow[b]{2}{*}{ Deaths } & \multirow{2}{*}{$\begin{array}{l}\text { SDR, per } \\
100000\end{array}$} & \multicolumn{2}{|l|}{ Model-based MRR } \\
\hline & & & & Model 1 & Model 2 \\
\hline 2 & 2715934 & 2457 & 88.1 & $1.35^{\star \star \star}(1.27-1.43)$ & 1.05 (0.99-1.11) \\
\hline 4 & 2826513 & 2170 & 73.0 & $1.11^{\star \star \star}(1.05-1.18)$ & 1.01 (0.95-1.08) \\
\hline 5 & 2835399 & 2030 & 65.6 & 1.00 (ref) & 1.00 (ref) \\
\hline
\end{tabular}

$\mathrm{P}<0.01^{\star \star *} ; 0.01<\mathrm{P}<0.05^{\star *}$

Model 1-adjusted for age; model 2 -adjusted for age and all other variables.

Confidence intervals are presented in the parentheses.

unemployment as well as the education and income gradients are substantially attenuated in the fully adjusted model 2.

In model 2, living in West Germany is associated with a higher mortality risk among females. Like for males, the risk of dying for females is twice as high among citizens than among non-citizens, and among the unemployed than among the employed. The educational mortality gradient among females is very consistent. Although mortality risk is clearly elevated in the lowest income quintile, across other quintiles female mortality declines only weakly in model 1 , and does not change in a regular manner in model 2.

More information on the distribution of the population at risk, death counts by ages and age-specific mortality rates by SES are given in the online supplementary appendix 1.

\section{Combined mortality risks}

To estimate the combined MRRs, we first run additional regression models separately for East and West Germany (see the results in the online supplementary appendix 2). The mutually adjusted MRRs for education (four categories) and income (five categories) were then used to calculate the combined MRRs across $20(4 \times 5)$ combinations of the categories of the two variables. For example, the combined MRR for East German males with secondary education and in income quintile 3 is estimated as follows:

$\mathrm{MRR}=\exp (\ln (1.12)+\ln (1.55))=1.74$, where 1.12 and 1.55 are the point estimates of the HRs for the secondary education and the third income quintile, respectively (see online supplementary appendix 2).

Figure 2 summarises the obtained two-dimensional MRR estimates and provides an overview of mortality disparities in Germany by means of the population risk profile.

The first segment of the black line in the left-hand panel of figure 2 shows an MRR of 8.1. This reflects the finding that in East Germany, the most disadvantaged male population group (income quintile 1, unknown education; $14.2 \%$ of the total population) has a mortality risk that is 8 times higher than that of the vanguard group (income quintile 5, higher education; $4.7 \%$ of the total population). The highest risk group in West Germany makes up $11 \%$ of the population and has an MRR of 5.5. Among females in East Germany, the group with the highest MRR (income quintile 1, unknown education; $11.4 \%$ ) has a mortality risk that is 5 times higher than that of the vanguard group. The corresponding MRR for females residing in West Germany is 3.8.

\section{Sensitivity analyses}

We carried out sensitivity analyses of possible influences on the results: 1) of the non-inclusion of the EMR population and 2) of the large share of unknown (missing) values for the education variable.

\section{Non-inclusion of EMR population}

Disabled pensioners of working ages (as reflected by EMR data) are not included in the analysis, which may result in somewhat biassed estimates of SES-related mortality differences. To address this issue, we performed an experiment by distributing the EMR population and deaths across socioeconomic categories of the active population
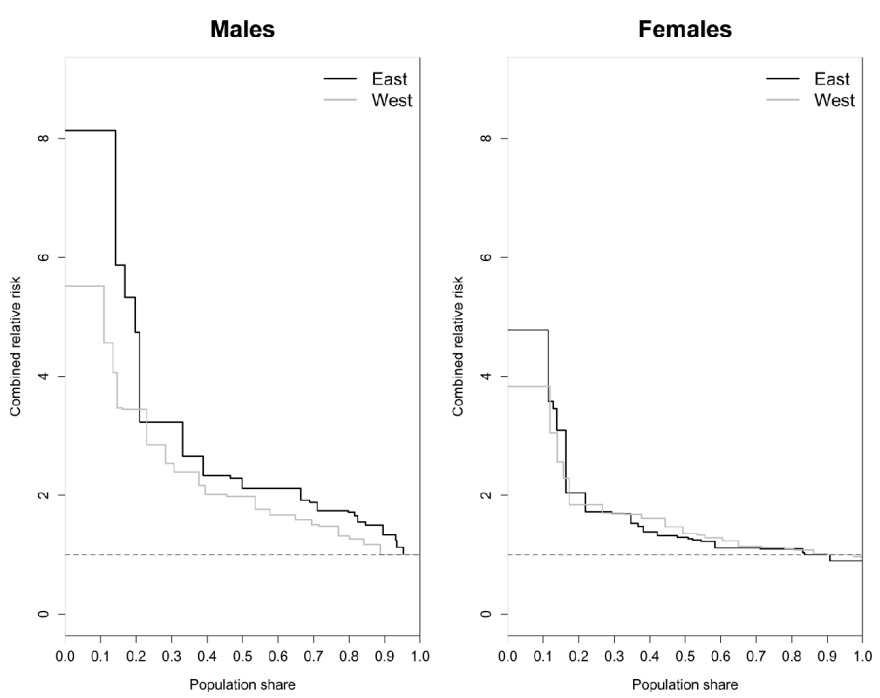

Figure 2 Combined relative risk and corresponding population shares by sex; East and West Germany, ages 30-59 years, 2013. Based on all 20 possible combinations of categories of education (4) and income quintile (5). 
Table 2 Age-adjusted mortality rate ratios for education before and after the redistribution of the unknown educational category, ages 30-59 years, 2013

\begin{tabular}{|c|c|c|c|c|}
\hline \multirow[b]{2}{*}{ Education } & \multicolumn{2}{|l|}{ Males } & \multicolumn{2}{|l|}{ Females } \\
\hline & Initial & After imputation & Initial & After imputation \\
\hline Higher & 1.00 (ref) & 1.00 (ref) & 1.00 (ref) & 1.00 (ref) \\
\hline Lower & $1.67^{\star \star \star}(1.60-1.75)$ & $1.69^{\star \star \star}(1.64-1.75)$ & $1.45^{\star * \star}(1.35-1.55)$ & $1.65^{\star \star \star}(1.57-1.74)$ \\
\hline Unknown & $2.72^{\star \star \star}(2.61-2.84)$ & - & $2.15^{\star \star \star}(2.02-2.29)$ & - \\
\hline
\end{tabular}

$\mathrm{P}<0.01^{\star \star *} ; 0.01<\mathrm{P}<0.05^{\star *}$

Confidence intervals are presented in the parentheses.

(AKV) assuming that disabled individuals are more prevalent at lower SES levels. We used three scenarios in which we assumed that the share of the EMR population increases as SES decreases. For scenario 1, we assumed that the share of EMR individuals in the highest SES group (higher education and the fifth income quintile) is $50 \%$ lower than that in the AKV population. Because the EMR population is small (about $4 \%$ of the total population), its redistribution did not result in notable changes in the composition of the total population; instead, it just somewhat increased mortality levels in all education-income groups. Altering the initial EMR/AKV distribution ratio parameter for the vanguard group from $50 \%$ to $25 \%$ (scenario 2), or even to $10 \%$ (scenario 3), also did not result in dramatic changes in the mortality distribution across the combined groups. More details are provided in the online supplementary appendix 3 .

\section{Missing values for the education variable}

To find out what would happen to the mortality rate ratios of education categories after a reasonable redistribution of the unknown values, we performed a sensitivity analysis. For the reasons discussed in details in online supplementary appendix 4, we did not rely on simple approaches such as complete-case analysis, the proportional redistribution of unknowns and assigning unknowns to the lowest educational category. Instead, the missing observations were imputed using the MICE imputation algorithm. ${ }^{34}$ Table 2 shows the age-adjusted effects of education on mortality obtained on the basis of the two datasets: 1) initial (with the unknown category) and 2) after imputation (without the unknown category).

The redistribution of the unknown educational category did not have a notable influence on the results for males. For females, the relative risk increased slightly in both the secondary and higher categories that is, the redistribution strengthened rather than weakened the educational mortality gradient.

\section{DISCUSSION}

\section{Main findings}

The mortality disparities among the German working-aged population are strongly associated with inter-individual differences in income. Although the income-related mortality gradient is more consistent among males, the death hazard in the lowest income quintile is greatly elevated for both sexes-nearly fivefold for males and threefold for females in the unadjusted models. In the fully adjusted model, the income gradient persists among men and is inconsistent among women. This finding, which merits further study, may be influenced by the insufficiency of the individual income variable for many women whose wealth depends on other household members. Thus, when studying females, it may be more appropriate to use household-based income measures. ${ }^{35}$ We also found that the income-related mortality gradient is more pronounced at midlife than at older ages. ${ }^{18}$

The unadjusted risk of dying was shown to be 3 times higher among unemployed males and females than among their employed counterparts. After controlling for income, education and other covariates, the relative risk was reduced to a factor of 2 . These results are compatible with those reported by a meta-analysis of the relationship between unemployment and all-cause mortality, but only for males. ${ }^{36}$ Our estimates for females, however, are higher than those of Roelfs $e t$ al. ${ }^{36}$ Moreover, unlike other studies, we found that excess relative risk due to unemployment is nearly identical for German males and females.

This is the first study to investigate the population-level mortality impacts of education in Germany. In the unadjusted models, the pronounced educational effects on mortality are in the expected direction. Our finding that the educational gradient among males weakens in the fully adjusted model suggests that the relationship between income and male mortality is substantially mediated by education.

Our results support the existence of a 'healthy migrant effect' ${ }^{37}$ After adjusting for socioeconomic and other variables, we found that non-citizens of working age were half as likely to die as German citizens. The increased (relatively to model 1) advantage of non-citizens is explained by the fact that in spite of having lower SES foreigners experience lower mortality compared with Germans. The additional tabulation based on the AKV data (not shown here) indicates a substantial disadvantage of foreigners in terms of current income: for both males and females about $40 \%$ of the foreign population falls into the first 
income quintile and only less than one-tenth to the fifth income quintile. The corresponding figures for the German citizens constitute $17 \%$ and $22 \%$.

The fully adjusted models indicate that although some mortality effects attenuate after mutual adjustment, most remain large. This implies that each of the SES variables provides information on 'general well-being' and on more specific health risks solely related to the particular variable. ${ }^{22}$ Therefore, using an aggregate risk measure combining income and education is justifiable. We found that individuals in the lowest income group and with the unknown and lower education face the highest mortality risks. By contrast, the vanguard group was shown to consist of individuals who are highly educated and belong to the fifth income quintile. The results also indicated that mortality disparities are more pronounced among males than among females, and are particularly large among East German males.

The analysis of unadjusted mortality risks revealed that East German females have a slight advantage that increases once all variables are controlled for. Some studies have attributed this advantage to higher rates of female smoking in the West than in the East. ${ }^{38}$ Notably, the disadvantage found among East German males disappears after controlling for individual SES characteristics. This finding suggests the East-West mortality difference in adult mortality is driven by the higher SES of men living in the West.

Our findings are consistent with the study of all Swedish employees in the age range $35-59$ years. ${ }^{22}$ Likewise, we have reported more pronounced mortality disparities among men, clear net associations between education and mortality for both sexes and the strong net association between individual income from work in men but not in women. Our results are also consistent with previous research on mortality differentials by SES in Germany, ${ }^{39}$ even though these analyses differed from our study in terms of the methods and data used and the populations analysed. In line with the results of the study by Luy et al, ${ }^{12}$ we found a strong association between SES and mortality that is more pronounced among males than among females. We also identified clear mortality gradients for both income and education, as the findings indicate that the risk of dying increases with decreasing income and level of educational attainment.

\section{Strengths and limitations}

To our knowledge, this analysis provides the first population-level evidence on socioeconomic mortality differentials among Germany's working-age population. Using large administrative data of the German pension insurance system, we assessed the mortality disparities using a broad range of socioeconomic and demographic characteristics, including individual income, education, employment status, citizenship and region for the year 2013. As no notable changes in adult mortality in Germany have occurred since 2013, analysing more recent data would not be expected to affect our main conclusions. The data used in our analysis, particularly on individual income, are highly reliable because the information reported by employers serves as the basis for pension entitlements in the future.

Several study limitations must be taken into account while interpreting the results. The most important of them are attributable to the limitations of the administrative data used in the analysis, over which we have no influence. First of all, our analyses do not cover individuals of working ages who are receiving pensions due to disability (EMR population). This implies that our results might not be directly comparable with many other studies on health inequalities. Nevertheless, the performed sensitivity analysis suggests that the hypothetical inclusion of this population would not affect our conclusions. Second, a large proportion of the data for the education variable was missing. The sensitivity analysis has shown that a plausible redistribution of this high-risk category among the three well-defined categories does not substantially change the relative risks of the lower and secondary educational categories. Third, our analysis refers to one calendar year so that there is no time lag between the exposure to risk factors and the event (death) implying that the numerical regression outputs should be seen as cross-sectional associations. Fourth, the individual income variable used in this study might be insufficient for assessing mortality differentials among women; household-based income measures could be more appropriate. Fifth, the definition of unemployment in the DRV data is too sensitive so that the pronounced mortality effects of unemployment found in our study should be seen as conservative estimates.

Several other caveats should be also mentioned. The two-dimensional (combined) disparity profile (figure 2) was based on the assumption that the mortality impacts of education and income are independent. Some studies have, however, found interactions between the health effects of education and income. ${ }^{40}{ }^{41}$ While our previous study ${ }^{18}$ and our own additional analysis (not shown here) has confirmed the statistical significance of some education-income interactions in Germany, these interactions produce only minor effects at the population level. The model-based 'inequality stairs' in figure 2 are in line with the empirical (non-parametric) estimates of the risk across education-income groups (analysis not shown here). Because the distinction between East and West is based on the current residence, some selection effects due to migration of healthier people from East to West are possible. Finally, analysing the effects on mortality of occupation, which is an important SES dimension, was beyond the scope of this paper. Because of both the complex structure of the KldB2010 classification of professions and the large gaps in the coverage of the Tätigkeitsschlüssel, this dimension could not be included in this study. However, examining mortality differentials by occupational class is an important direction for future research, as international studies ${ }^{42}$ and research on mortality differentials in Germany ${ }^{12}$ have shown. 


\section{Conclusions}

Low SES is a major determinant of excess adult mortality in Germany. The results of this study are relevant for identifying components of the remaining East-West mortality differences within Germany. These differences are large for males only, and can be explained by the higher SES of men living in the West, rather than by contextual differences between the two parts of the country. However, as long as a male life expectancy gap between the two parts of Germany persists, it merits the attention of policy-makers. The further monitoring and analysis of these differences, which can be performed using DRV data, should be prioritised.

Contributors PG, RS and VS designed the study. RS arranged the work with individual-level data at the FDZ, and supplied the data in the form of a frequency table. PG performed the statistical analysis and drafted the manuscript which was revised by RS and VS. All authors read and approved the final version of the manuscript.

Funding VS was partly supported by the programme of state support of leading universities of the Russian Federation '5-100'.

Competing interests None declared.

Patient consent for publication Not required.

Provenance and peer review Not commissioned; externally peer reviewed.

Data availability statement Data may be obtained from a third party and are not publicly available.

Open access This is an open access article distributed in accordance with the Creative Commons Attribution Non Commercial (CC BY-NC 4.0) license, which permits others to distribute, remix, adapt, build upon this work non-commercially, and license their derivative works on different terms, provided the original work is properly cited, appropriate credit is given, any changes made indicated, and the use is non-commercial. See: http://creativecommons.org/licenses/by-nc/4.0/.

\section{REFERENCES}

1. Mackenbach JP. Health Inequalities: Europe in Profile. Report of the project "Tackling Health Inequalities: Governing for Health". The European Commission, 2006.

2. Mackenbach JP, Kunst AE, Cavelaars AE, et al. Socioeconomic inequalities in morbidity and mortality in Western Europe. The EU Working group on socioeconomic inequalities in health. Lancet 1997;349:1655-9.

3. Mackenbach JP, Bos V, Andersen O, et al. Widening socioeconomic inequalities in mortality in six Western European countries. Int $J$ Epidemiol 2003;32:830-7.

4. Shkolnikov VM, Andreev EM, Jdanov DA, et al. Increasing absolute mortality disparities by education in Finland, Norway and Sweden, 1971-2000. J Epidemiol Community Health 2012;66:372-8.

5. Marmot M, Allen J, Bell R, et al. Who European review of social determinants of health and the health divide. The Lancet 2012;380:1011-29.

6. Huisman Met al. Socioeconomic inequalities in mortality among elderly people in 11 European populations. J Epidemiol Community Health 2004;58:468-75.

7. Mackenbach JP, Kulhánová I, Menvielle G, et al. Trends in inequalities in premature mortality: a study of 3.2 million deaths in 13 European countries. J Epidemiol Community Health 2015;69:207-17.

8. Mackenbach JP, Martikainen P, Menvielle G, et al. The arithmetic of reducing relative and absolute inequalities in health: a theoretical analysis illustrated with European mortality data. J Epidemiol Community Health 2016;70:730-6.

9. Mackenbach JP, Kulhánová I, Artnik B, et al. Changes in mortality inequalities over two decades: register based study of European countries. BMJ 2016;353.

10. Klein T. Mortalität in Deutschland aktuelle Entwicklungen und soziale Unterschiede. In: Zapf WJ, Schupp R, eds. Lebenslagen Im Wandel. Sozialberichtserstattung Im Längsschnitt. New York, 1996: 366-77.

11. Reil-Held A. Einkommen und Sterblichkeit in Deutschland: Leben Reiche länger? In: Institut für Volkswirtschaftslehre und
Statistik, Universität Mannheim, Beiträge Zur angewandten Wirtschaftsforschung, 2000: 580-00.

12. Luy M, Wegner-Siegmundt $C$, Wiedemann A, et al. Life expectancy by education, income and occupation in Germany: estimations using the longitudinal survival method. Comparative Population Studies 2015;40:399-436.

13. Kroh M, Neiss H, Kroll L, et al. Menschen MIT hohen Einkommen leben länger. DIW Wochenbericht 2012;38.

14. Lampert T, Kroll L, Dunkelberg A. Soziale Ungleichheit Der Lebenserwartung in Deutschland. Aus Politik und Zeitgeschichte 2007;42:11-18.

15. Mielck A. Soziale Ungleichheit und Gesundheit: Einführung in die aktuelle Diskussion. Bern: Huber, 2005.

16. Kroll LE, Lampert T. Soziale Unterschiede in Der Lebenserwartung. Datenquellen in Deutschland und Analysemöglichkeiten des SOEP. Methoden - Daten - Analysen 2009;3:3-30.

17. von Gaudecker H-M, Scholz RD. Differential mortality by lifetime earnings in Germany. Demogr Res 2007;17:83-108.

18. Shkolnikov VM, Scholz R, Jdanov DA, et al. Length of life and the pensions of five million retired German men. Eur $J$ Public Health 2007;18:264-9.

19. Kibele EUB, Jasilionis D, Shkolnikov VM. Widening socioeconomic differences in mortality among men aged 65 years and older in Germany. J Epidemiol Community Health 2013;67:453-7.

20. Wenau G, Grigoriev P, Shkolnikov V. Socioeconomic disparities in life expectancy gains among retired German men, 1997-2016. J Epidemiol Community Health 2019;73:605-11.

21. Geyer Set al. Education, income, and occupational class cannot be used interchangeably in social epidemiology. Empirical evidence against a common practice. J Epidemiol Community Health 2006;60:804-10.

22. Torssander J, Erikson R. Stratification and Mortality--A Comparison of Education, Class, Status, and Income. Eur Sociol Rev 2010;26:465-74.

23. Grigoriev P, Pechholdová M. Health convergence between East and West Germany as reflected in long-term cause-specific mortality trends: to what extent was it due to reunification? Eur J Popul 2017;33:701-31.

24. Börsch-Supan A, Wilke CB. The German pension system: how it was, how it will be. NBER working paper, 2004: 10525.

25. Lühning R. Entwicklungen des Leistungsrechts Der gesetzlichen entenversicherung in Der Bundesrepublik Deutschland seit Der großen Rentenreform von 1957 (1957-2004. Logos Verlag Berlin, 2006.

26. FDZ-RV. German federal pension fund, 2016. Available: https://www. eservice-drv.de/FdzPortalWeb/

27. Himmelreicher RK, Gaudecker HM, Scholz RD. Nutzungsmöglichkeiten von Daten der gesetzlichen Rentenversicherung über das Forschungsdatenzentrum der Rentenversicherung (FDZ-RV). Eine Beschreibung von Nutzungsmöglichkeiten an Hand des Projektes: "Differentielle Sterblichkeit". MPIDR Working Paper WP 2006.

28. Scholz RD, Schulz A. Haben Arbeitslosigkeit und Arbeitsunfähigkeit einen Einfluss auf die Höhe der Lebenserwartung?

Bevölkerungsforschung, 9-22. Bonn: GESIS-IZ Sozialwissenschaften, 2009.

29. Mortality. Human mortality database (HMD), 2016. Available: www. mortality.org

30. Code Table of Occupation. Schlüsselverzeichnis für die Angaben zur Tätigkeit in den Meldungen zur Sozialversicherung, 2010.

31. Jasilionis D, Shkolnikov VM. Longevity and education: a demographic perspective. Gerontology 2016;62:253-62.

32. Kunst AE, Groenhof F, Borgan JK, et al. Socio-economic inequalities in mortality: methodological problems illustrated with three examples from Europe. Rev Epidemiol Sante Publique 1998;46:467-79.

33. Waterhouse JAH, Muir CS, Cornea P, et al. Cancer incidence in five continents. Lyon: international agency for research on cancer. , 1976: Vol III, 454-9.

34. Buuren Svan, Groothuis-Oudshoorn K. Mice: Multivariate Imputation by Chained Equations in R. J Stat Softw 2011;45:1-67.

35. Geyer S. Income, income, or income? the effects of different income measures on health in a national survey. J Epidemiol Community Health 2011;65:491-6.

36. Roelfs DJ, Shor E, Davidson KW, et al. Losing life and livelihood: a systematic review and meta-analysis of unemployment and all-cause mortality. Soc Sci Med 2011;72:840-54.

37. Razum O, Zeeb H, Akgün HS, et al. Low overall mortality of Turkish residents in Germany persists and extends into a second generation: merely a healthy migrant effect?*. Trop Med Int Health 1998;3:297-303. 
38. Lampert T, Hoebel J, Eric Kroll L, et al. Soziale Unterschiede in Der Lebenserwartung. Public Health Forum 2018;26:325-7.

39. Myrskylä M, Scholz R. Reversing East-West mortality difference among German women, and the role of smoking. Int J Epidemiol 2013;42:549-58.

40. Mirowsky J, Ross CE. Education, social status, and health. New Brunswick: Transaction Publishers, 2003.
41. Schnittker J. Education and the changing shape of the income gradient in health. J Health Soc Behav 2004;45:286-305.

42. Stringhini S, Carmeli C, Jokela M, et al. Socioeconomic status and the $25 \times 25$ risk factors as determinants of premature mortality: a multicohort study and meta-analysis of 1.7 million men and women. The Lancet 2017;389:1229-37. 